\title{
Assessment of Pathological Personality traits in Meditation Practitioners and Non-practitioners
}

\author{
Lucas de Francisco Carvalho \\ Universidade São Francisco, \\ Campinas-SP, Brazil
}

\author{
Wellington Arruda \\ Universidade São Francisco, \\ Campinas-SP, Brazil
}

\begin{abstract}
This study aimed to evaluate and compare pathological personality traits in meditation practitioners and non-practitioners. Therefore, data were collected from 104 participants of both sexes aged over 18 years, including 53 practitioners of concentrative and mindfulness meditation styles, and 51 non-practitioners. Participants responded to the Dimensional Clinical Personality Inventory (IDCP), the Brazilian version of the Personality Inventory for DSM-5 (PID-5), and an anamnesis questionnaire about the practice of meditation; we proceeded to repeated ANOVA measures and logistic regression analysis to verify the study's goals. Overall, higher means were observed for non-practitioners in the dimensions/factors of the tests, and specific pathological traits as best predictors of the participating groups (practitioners versus non-practitioners). The results indicated that the meditators tended to have lower intensity of pathological personality traits.
\end{abstract}

Keywords: personality traits, mindfulness, meditation, psychological assessment, pathological personality

\section{Avaliação das Características Patológicas da Personalidade em Praticantes e não Praticantes de Meditação}

\begin{abstract}
Resumo: O presente estudo tem como objetivo avaliar e comparar características patológicas da personalidade em praticantes e não praticantes de meditação. Para tanto, os dados foram coletados com 104 participantes, de ambos os sexos e com idade igual ou superior a 18 anos, sendo 53 praticantes de escolas de meditação de estilos concentrativo e mindfulness, e 51 participantes não praticantes. Os participantes responderam ao Inventário Dimensional Clínico da Personalidade (IDCP), ao Personality Inventory for DSM-5 (PID-5) e a um questionário de anamnese sobre prática da meditação. Procedeu-se à ANOVA por medidas repetidas e análise de regressão logística para verificação dos objetivos da pesquisa. No geral, foram observadas médias mais elevadas pelos não praticantes nas dimensões/fatores dos instrumentos aplicados, além de traços patológicos específicos como melhores preditores dos grupos de participantes (praticantes versus não-praticantes). Os resultados indicaram que os praticantes de meditação tendem a apresentar menor intensidade de características patológicas da personalidade.
\end{abstract}

Palavras-chave: traços de personalidade, mindfulness, meditação, avaliação psicológica, personalidade patológica

\section{Evaluación de las Características Patológicas de la Personalidad en Practicantes y no Practicantes de Meditación}

\begin{abstract}
Resumen: Este estudio tiene como objetivo evaluar y comparar las características patológicas de la personalidad en los practicantes y no practicantes de meditación. Los datos fueron recolectados en una muestra de 104 sujetos de ambos sexos mayores de 18 años, de los cuales 53 eran practicantes de escuelas de meditación de estilos concentrativos y mindfulness, mientras que los restantes 51 eran no practicantes. Los sujetos respondieron el Inventario Dimensional Clínico de Personalidad (IDCP), la versión brasileña del Personality Inventory for DSM-5 (PID-5) y un cuestionario de anamnesis sobre la práctica de la meditación. Igualmente, se procedió al ANOVA por medidas repetidas y al análisis de regresión logística para verificar los objetivos de la investigación. En general, fueron observadas medias más elevadas por los sujetos no practicantes en las dimensiones/factores de los instrumentos aplicados, además de trazos patológicos específicos como mejores predictores de los grupos de participantes (practicantes versus no practicantes). Los resultados indicaron que los practicantes de meditación tienden a presentar menor intensidad de características patológicas de la personalidad.
\end{abstract}

Palabras clave: rasgos de personalidad, mindfulness, meditación, evaluación psicológica, personalidad patológica

Meditation is under stood as a self-regulating activity that can bring physical and psychological benefits to its practitioner. Studies have shown (Campanella,

${ }^{1}$ Correspondence address: Rua Waldemar César da Silveira, 105, Jardim Cura D'Ars (SWIFT), Campinas-SP, Brazil. CEP 13.045-510. E-mail: lucas@labape.com.br
Crescentini, Urgesi, \& Fabro, 2014) that meditation practitioners tend to present psychological profiles, and more specifically, personality profiles, with more attenuated pathological characteristics compared to non-practitioners. However, there is still little information as to which pathological traits of the personality are specifically related to the practice of meditation. In addition, considering the 
country of origin of the sample (i.e., Brazil), the data collected are even scarcer (Menezes, 2009). In order to contribute to this field of study, the present research sought to investigate the personality profile of people who practice meditation, comparing with non-practitioners of this activity, using for this purpose instruments for the evaluation of pathological personality characteristics.

Pathological personality traits are conceptually located at the extreme end of the personality-trait continuum (Schroeder, Wormworth, \& Livesley, 1992), characterized by maladaptive functioning, with significant losses in the attempt to cope with daily demands (T. Millon, 2011). The functioning of pathological personality can be characterized by three main elements (T. Millon, Grossman, C. M. Millon, Meagher, \& Ramnath, 2004): adaptive inflexibility, vicious circle, and tenuous stability. Adaptive inflexibility refers to rigid and very limited behavioral patterns employed to achieve objectives, relate to others, or cope with stressful situations; the vicious circle relates to perceptions and needs that perpetuate and intensify pre-existing difficulties; and the tenuous stability is related to a lower resilience of the individual against stressful situations.

The literature presents several procedures and interventional techniques for maladaptive psychological functioning. Among them, there is meditation, which is a simultaneous process of observation and misidentification, that is, a metacognitive process by part of the individual's consciousness in relation to mental contents (Kabat-Zinn, 2003; Menezes, 2009; Paul, Stanton, Greeson, Smoski, \& Wang, 2012).

Tang et al. (2007) define meditation as a self-regulating practice, which causes physical and mental relaxation induced by the practitioner himself. In meditative practices there are active and passive modalities, the former involving physical movements, and the latter involving sitting and silent practices.

The differentiation between the different styles of meditative practices is not consensual in the scientific literature. Among them, meditative practices can be defined by means of two styles, concentration and mindfulness. Mindfulness meditation, according to Kabat-Zinn (2003), is the essence of Buddhist meditation, in which thefull consciousness of each moment, openly, non judgmentally and with the attention focused to the perception of stimuli. According to this definition, in the mindfulness style, the objective is the self-regulation of attention and the openness and acceptance of the present moment, being therefore, often disconnected from the spiritual search inherent to oriental practices of meditation (Kabat-Zinn, 2003; Menezes, 2009; Shapiro, Carlson, Astin, \& Freedman, 2006). Mindfulness refers, therefore, to the nonjudgmental open monitoring of automatic thoughts and reflections for the perception of stimuli. Differently, concentration-style meditation refers to the total concentration in a single external or internal focus that may be an external or internal object (thought, feeling, emotion, breathing, images, symbols and mantras) (Menezes \& Dell'Aglio, 2009).
We chose the definition that involves the distinction between the concentration and mindfulness meditation styles, since this study contemplates both styles in the sample design. However, different meditative practices share the common goal of achieving some understanding or perception of aspects of the dynamics of the mind and reality. In seeking these apprehensions about the psychological state, the practitioner benefits from states of balance and harmony in his personality patterns and in other psychological aspects. In this point, emphasized by Menezes (2009), lies the main point of convergence between psychology and meditation in the promotion of mental health, in either the prevention or significant reduction of physiological and psychological symptoms.

Meditative practices have been adopted in public health policies, as pointed out by Noguchi (2015), and have presented effective results for the promotion of health in the treatments of addictions and compulsions, hypertension, diabetes, Alzheimer's disease among other demands, besides favoring the development of humanized aspects in health professionals and an attitude of autonomy and self-care in patients. For example, Mindfulness-Based Cognitive-Behavioral Therapy (MBCT) has been used with good results in patients with various disorders, both in individual and group sessions. Zylowska et al. (2008), for example, found evidence of improvement in attention and impulse control in people with ADHD who underwent training in mindfulness; there are also studies on the effectiveness of this practice for cases of symptoms of anxiety, stress, depression, among others (KabatZinn, 2003; Khoury et al., 2013; Paul et al., 2012). Despite all the gains associated with the practice of meditation, which are scientifically recognized in the international community, the studies on meditation are scarce in the Brazilian scientific setting, as observed by Menezes (2009).

In addition, there are few empirical studies that relate to the specific scope of the present study: the relationship between meditation and pathological personality traits. Campanella et al. (2014) investigated the possible influence of the effects of an eight-week mindfulness practice training on a sample divided into four groups of participants, two groups consisting of participants who practiced mindfulness on a consistent and daily basis; a group of participants who practiced mindfulness in a less engaged way, without practicing it at home; and a control group without any kind of training or practice in meditation or mindfulness. Using a rating scale of temperament and character, three personality facets were measured, focusing on the intrapersonal (selfdirected), interpersonal (cooperative), and transpersonal (selftranscendence) aspects, pre and post training in mindfulness. Statistically significant differences were found in all the characteristics evaluated by the inventory, compared to the control group, without training. In this sense, it was verified that the participants of the group who practiced mindfulness in a more engaged way obtained higher scores in the scale of temperament and character, which suggests a more adequate/ healthy psychological functioning. It was concluded in this study that the practices that favor the development of more 
mature psychological mechanisms, such as mindfulness, can favor the development of the personality.

The effects of meditation on personality traits were also verified by Menezes (2009), using the Personality Factor Battery (PFB), which is based on the Five Great Factor Model (FGF). This study showed the interaction between personality traits and psychological well-being, as assessed by the General Health Questionnaire (GHQ), provided by meditation practice. It was observed that with the increase in psychological well-being caused by meditative practice, significant changes occurred in the dimensions Extraversion, Neuroticism and Conscientiousness. Data from this research also showed that the Neuroticism traits have a negative correlation with the effects of meditation on psychological well-being and Conscientiousness, a positive correlation. The level of the Extraversion dimension increased significantly, associated with the increase in psychological well-being provided by the practice of meditation.

In the study conducted by Fossati, Porro, Maffei and Borroni (2012) the impact of mindfulness practice was also verified; however, in relation to the levels of awareness and attention and the presence of personality disorders in a clinical sample. The following instruments were used in a clinical sample of 111 patients: the Personality Diagnostic Questionnaire-4 + (PDQ-4 +), the Structured Clinical Interview for DSM-IV Axis II Personality Disorders (SCID-II), the Mindful Attention Awareness Scale, the Five Facet Mindfulness Questionnaire, and the Questionnaire Act with Awareness. There was a negative relationship between level of awareness and attention and the presence of symptoms of personality disorders, especially borderline personality disorder.

Van den Hurk et al. (2011) conducted a study in which 35 experienced meditators with a mean practice time of 13 years were compared to a control group of 35 participants without any experience in meditation. Participants responded to the NEO-Five Factor Inventory (NEO-FFI) and the Kentucky Inventory of Mindfulness Skills (KIMS). Significant and positive correlations were found between the practice of meditation and the Openness and Extraversion factors, as well as negative correlations with Neuroticism and Conscientiousness; in relation to the group of meditators, there were high levels of curiosity and receptivity to new experiences and experience of positive affect, with less proneness toward negative emotions and worrying, as well as a reduced focus on achievements.

Data obtained by Leung and Singhal (2004) also presented significant differences in the personality of practitioners and non-practitioners of other types of meditation. The scores obtained in the Eysenck Personality Inventory (EPI) by 80 experienced QiQong meditation practitioners (style commonly understood as pertaining to mindfulness) were compared to the results obtained by 74 non-meditator participants. There was a negative correlation between the practice of meditation and Neuroticism, even controlling for age, gender, and level of education. However, no significant correlation was found with the Extraversion factor. Results such as this suggest that as meditative practices are efficient in promoting personality traits that are potentially more beneficial to adjustment (e.g., reduction of the Neuroticism factor), the viability of meditation in promoting mental health is evident.

As can be observed, different studies have found data suggesting that the practice of meditation in general, and mindfulness in particular, are related to healthier psychological profiles compared to people who do not engage in either practices (Giluk, 2009). However, there is an important gap in the investigation of the relationship between pathological characteristics of the personality and the practice of meditation. In other words, while there are a reasonable number of studies relating healthy personality traits to meditation practice, the number of studies relating pathological personality traits to this practice is more modest. The present study aimed to evaluate and compare pathological characteristics of the personality in meditation practitioners and non-practitioners. Specifically, we investigated the personality profile in people who practice meditation, and compared it with that of non-practitioners, using instruments for the evaluation of pathological personality characteristics, the Clinical Dimensional Personality Inventory - IDCP (Carvalho \& Primi, 2015) and the Personality Inventory for DSM-5 - PID-5 (Krueger, Derringer, Markon, Watson, \& Skodol, 2011). According to the literature, it was hypothesized (h1) that the group of non-practitioners in this study would present higher scores in the dimensions of both instruments compared to the group of practitioners; and (h2) higher scores were expected in the group of non-practitioners mainly in dimensions/facets related to borderline functioning (IDCP: Mood Instability), but also in Dependence and Impulsivity (PID-5: Emotional Lability, Separation Insecurity and Impulsivity).

\section{Method}

\section{Participants}

The sample was composed of 104 participants, of whom 53 were meditation practitioners, encompassing the concentration and mindfulness styles of meditation, from meditation schools in the countryside of the state of São Paulo, and 51 non-meditator participants. The study participants were in the age range from 18 to 70 years $(M=47.96$; $S D=13.75)$ in the group of meditators andfrom 18 and 57 years $(M=22.25 ; S D=7.17)$ in the non-meditators group. In both groups the predominant ethnicity was Caucasian (77.4\% in practitioners and $74.5 \%$ in non-practitioners). In the practitioners group, $73.6 \%$ of participants were women and in the non-practitioners, $80.4 \%$ were women. Among meditators, schooling ranged from incomplete elementary school to complete higher education, and $26.4 \%$ reported having a degree in higher education. In then on-practitioners group, $62.7 \%$ reported attending higher education. Based on that test, we compared the mean of groups in the variables 
age, education, sex, psychiatric treatment, psychological treatment and use of psychotropic medication. We found statistical significance $(p<0.05)$ only for age $(t=11.575$; $d f=98)$ and psychiatric treatment $(t=1.429 ; d f=98)$.

Among meditators, $71.7 \%$ reported the practice of concentration meditation and $28.3 \%$, mindfulness meditation. The forms of meditation performed by participants were Yoga (45.3\%), Shinsokan (18.9\%), Twin Hearts (7.6\%), Rosary Meditation (1.9\%) and Transcendental Meditation (1.9\%) (concentration type); and Vipassana (11.3\%), Anapanasati (1.9\%) and Zen (1.9\%) (mindfulness). Among practitioners, $94.3 \%$ reported knowledge of the meditation technique for over a year. Regarding the frequency of practice, $43.4 \%$ reported practicing between three and six times a week and $56.6 \%$, every day. About the number of times per day of meditation practice, it ranged from one to more than four times a day, and $41.5 \%$ reported practicing once a day. The time used to practice meditation ranged from 5 minutes to more than 1 hour, and $49.1 \%$ reported practicing between 15 and 30 minutes.

Still in relation to practitioners, $15.1 \%$ reported being under psychiatric treatment, and only $3.8 \%$ reported having used psychotropic medication, and $41.5 \%$ reported having experienced psychotherapy. Suicide attempts were reported by $7.5 \%$ of practitioners and, in relation to suicidal ideation, $15.1 \%$ reported a history of suicidal ideation and $1.9 \%$ reported current suicidal ideation. In non-practitioners, $9.8 \%$ of the sample reported having already undergone psychiatric treatment, with only $2 \%$ reporting having used psychotropic medication and 53\%, psychotherapeutic treatment. In addition, suicide attempts were reported for $7.8 \%$, history of suicidal ideation for $11.8 \%$, and current suicidal ideation for $3.9 \%$.

\section{Instruments}

The Clinical Dimensional Personality Inventory (IDCP) (Carvalho \& Primi, 2015) was used to evaluate pathological personality traits through 12 dimensions (Dependence, Aggressiveness, Mood Instability, Eccentricity, Attention Seeking, Distrust, Grandiosity, Isolation, Avoidance of Criticism, Self-sacrifice, Conscientiousness and Impulsivity). It is a self-report inventory, composed of 163 items arranged in a four-point Likert scale, with answers ranging between "it has nothing to do with me" (1) and "it has a lot to do with me" (4), with administration time of approximately 25 minutes. The psychometric properties of the IDCP dimensions were investigated (Carvalho \& Primi, 2015, 2016; Carvalho, Primi, \& Stone, 2014) and showed adequacy. Specifically, evidence of validity was verified based on the internal structure and based on external variables and criteria, as well as alpha coefficients above .70 for most dimensions. In this study reliability by internal consistency (Cronbach's alpha) was higher than 0.70 for 11 of the 12 dimensions, except for the Conscientiousness dimension, which presented $\alpha=0.66$.

The Personality Inventory for DSM 5 was also applied (Krueger et al., 2011), which is also an inventory for self-report evaluation of pathological personality traits. It is composed of 220 items, distributed in 25 facets: Anhedonia, Anxiousness, Attention Seeking, Callousness, Deceitfulness, Depressively, Distractibility, Eccentricity, Emotional Lability, Grandiosity, Hostility, Impulsivity, Avoidance of Intimacy, Irresponsibility, Manipulativeness, Perceptual Dysregulation, Perseverance, Restricted Affectivity, Rigid Perfectionism, Risk Taking, Separation Insecurity, Submissiveness, Suspiciousness, Uncommon beliefs and experiences, and Avoidance. These items can be grouped into five dimensions: Negative Affectivity, Detachment, Antagonism, Disinhibition, and Psychoticism. Items are answered on a four-point Likert scale (being zero equal to "very false or often false" and three equal to "very true or often true"). The instrument was developed to measure criterion B of the current proposal for the evaluation of personality disorders for the DSM-5.No Brazilian studies were found demonstrating the adequacy of the psychometric properties of the instrument, only an unpublished version adapted to Brazil (Primi et al., 2013); however, international data are favorable (Krueger et al., 2011), including evidence of validity based on internal structure and external variables, as well as adequate reliability indices. In the present research, all facets presented Cronbach's alpha greater than .70, except for Grandiosity $(\alpha=.62)$, Irresponsibility $(\alpha=.64)$ and Suspiciousness $(\alpha=.52)$.

Finally, a questionnaire prepared by the researchers was also applied to verify whether or not the study participants practiced meditation, practice time, and other relevant details about the meditative practice.

\section{Procedure}

Data collection. Participants responded to the questionnaire created by the researchers referring to the practice of meditation, the IDCP and the PID5. On average, it took 1 hour of administration. Nonpractitioners were accessed by convenience at a private university in the countryside of the State of São Paulo, in the institution's classrooms. Meditators responded in the sites of meditation practice (three schools for meditation practice, one study center with meditation classes, and three practice groups for meditation study) or in the university campus. In all cases, collections were collective, with up to 30 simultaneous administrations.

Data analysis. For the investigation of hypotheses 1 and 2, we used ANOVA by repeated measurements with the SPSS software, including a measure of effect size $(d)$, separately by test (IDCP and PID-5). It should be noted that based on the ANOVA by repeated measurements, tables with the descriptive data of the groups are presented in the psychological measurements. Although repeated measures ANOVA presented only one significance test for the observed profile, effect sizes were calculated (i.e., Cohen's d) for all comparisons. Furthermore, logistic regression analysis was performed to verify which IDCP and PID-5 dimensions, together, better predict the participants' group (it is emphasized that no 
multicollinearity was found for the independent variables used); we also performed comparisons between means (ANOVA) in an exploratory way, investigating possible differences in subgroups of practitioners established from data collected.

\section{Ethical Considerations}

The project was approved by the Research Ethics Committee of the Universidad São Francisco (CAAE - 37484814.6.0000.5514). Participants agreed and signed the Free and Informed Consent Form, and the data is anonymous and confidential.

\section{Results}

According to the objectives of this study, the groups were compared by means of repeated measures ANOVA and the respective Cohen's d were calculated. The data can be seen in Table 1 for the IDCP dimensions and in Table 2 for the PID-5 dimensions.

Table 1

Means, Standard deviations and Cohen's $d$ of the Practitioners and Non-practitioners groups in the dimensions of the IDCP

\begin{tabular}{|c|c|c|c|}
\hline Dimensions & $\begin{array}{l}\text { Practitioners } \\
\quad(n=35) \\
M(S D)\end{array}$ & $\begin{array}{l}\text { Non-practitioners } \\
\qquad \begin{array}{c}(n=45) \\
M(S D)\end{array}\end{array}$ & $d$ \\
\hline Dependence & $1.44(0.30)$ & $1.93(0.56)$ & 1.05 \\
\hline Aggressiveness & $1.25(0.18)$ & $1.41(0.31)$ & 0.61 \\
\hline Mood Instability & $1.56(0.34)$ & $2.05(0.51)$ & 1.10 \\
\hline Eccentricity & $1.50(0.39)$ & $1.52(0.43)$ & 0.05 \\
\hline Attention Seeking & $2.14(0.30)$ & $2.21(0.44)$ & 0.18 \\
\hline Mistrust & $1.71(0.46)$ & $2.07(0.58)$ & 0.68 \\
\hline Grandiosity & $1.45(0.29)$ & $1.70(0.44)$ & 0.65 \\
\hline Isolation & $1.80(0.41)$ & $1.86(0.56)$ & 0.12 \\
\hline Avoidance of Criticism & $1.23(0.41)$ & $1.45(0.46)$ & 0.50 \\
\hline Self-sacrifice & $1.86(0.53)$ & $2.33(0.58)$ & 0.84 \\
\hline Conscientiousness & $2.43(0.46)$ & $2.44(0.36)$ & 0.02 \\
\hline Impulsivity & $1.15(0.18)$ & $1.61(0.50)$ & 1.04 \\
\hline
\end{tabular}

Note. $d \geq .20$ in bold.

The groups differed in the score of the IDCP dimensions $(F=5.4769 ; d f=6.733 ; p<.001)$, and the group of nonpractitioners scored higher in all 12 dimensions. The most discrepant differences in the means in the different dimensions can also be verified in the $d$ coefficients obtained, in relation to the higher scores by the group of non-practitioners in the dimensions Mood Instability, Dependence and Impulsivity.

Considering the dimensions that presented discrepancies between the groups, the highest means in the practitioners group were in the dimensions Self-sacrifice, Mistrust and Mood Instability, and the lowest ones were in the Impulsivity,
Avoidance to Criticism, and Aggressiveness dimensions. In the non-practitioners group the highest means were in the dimensions Self-sacrifice, Mistrust and Mood Instability, followed by the lowest means in this group in the dimensions Aggressiveness, Avoidance of Criticism, and Impulsivity.

For four dimensions the difference in the score between the two groups was not expressive, as indicated by Cohen's $d$ (effect size <.20), as follows: Eccentricity, Isolation, Conscientiousness and Attention Seeking. The graphical analysis of the participants' profiles can be visualized in Figure 1. 
Figure 1 shows that the profile complements the information in Table 1, demonstrating a quantitative differentiation of the groups, but with very similar profiles in terms of format. Nevertheless, some differences in the shape of the profiles can be verified, such as, for example, in the dimension Aggressiveness and Self-sacrifice.

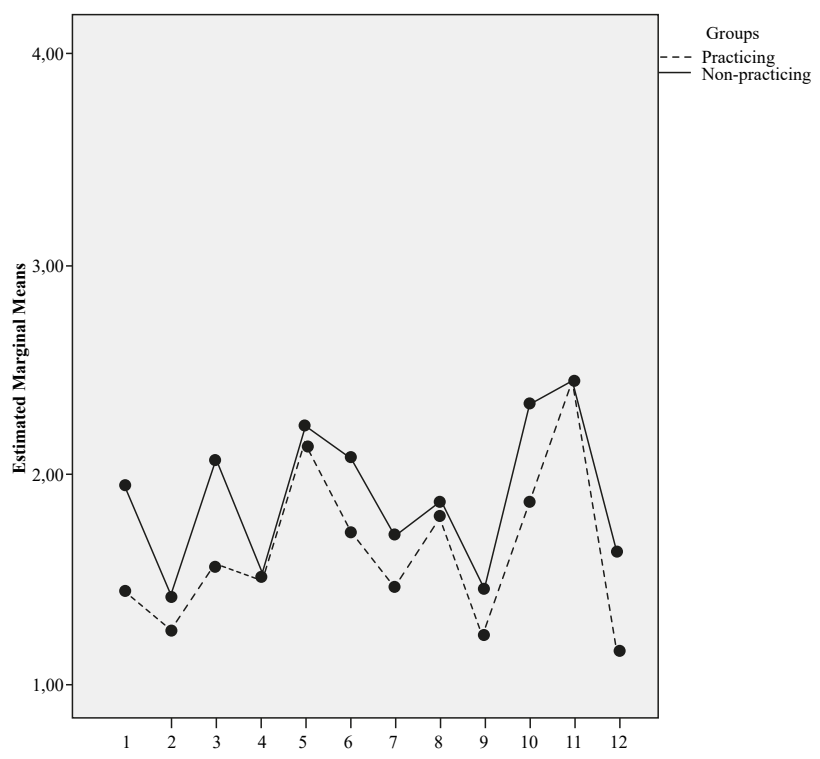

Figure 1. Profile of the groups in the IDCP dimensions 1. Dependency; 2. Aggressiveness; 3. Mood Instability; 4. Eccentricity; 5. Attention Seeking; 6. Mistrust; 7. Grandiosity; 8. Isolation; 9. Avoidance of Criticism; 10. Self-sacrifice; 11. Conscientiousness; 12. Impulsivity.

Next, as shown in Table 2, referring to the facets of PID-5, the groups are distinct in the pathological personality characteristics $(F=9.32, d f=9.82, p<.001)$. Practitioners, compared to non-practitioners, scored higher in the facets Intimacy Avoidance, Unusual beliefs and experiences, and Avoidance, i.e., meditation practitioners are more eccentric and avoidant. Non-practitioners achieved higher scores on the PID-5 facets in Anxiousness, Distractibility, Emotional Lability, Hostility, Separation Insecurity, and Suspiciousness.

Considering only the significant differences and with an effect size equal to or greater than .20, the highest means in the PID-5 dimensions for the practitioners group were in Unusual beliefs and experiences, Emotional Lability and Suspiciousness. The lowest means were in the facets Deceitfulness, Depressivity and Irresponsibility. In nonpractitioners, the highest and lowest means, respectively, were in Anxiety, Emotional Lability and Suspiciousness, and in Deceitfulness, Irresponsibility and Grandiosity. Complementarily, Figure 2 shows less similar profiles between the two groups, that is, the qualitative distinctions are more evident in the profiles in the PID-5. It may also be noted that meditators scored higher in some facets.
Table 2

Means, Standard Deviation and Cohen's doff the Practitioners and Non-practitioners in the Dimensions of the PID-5

\begin{tabular}{|c|c|c|c|}
\hline Dimensions PID-5 & $\begin{array}{l}\text { Practitioners } \\
\quad(n=40) \\
M(S D)\end{array}$ & $\begin{array}{l}\text { Non-practitioners } \\
\qquad \begin{array}{c}(n=39) \\
M(S D)\end{array}\end{array}$ & $d$ \\
\hline Anhedonia & $1.51(0.34)$ & $1.76(0.57)$ & 0.53 \\
\hline Anxiety & $1.56(0.32)$ & $2.47(0.72)$ & 1.64 \\
\hline Attention Seeking & $1.38(0.43)$ & $1.67(0.61)$ & 0.55 \\
\hline Callousness & $1.22(0.32)$ & $1.21(0.17)$ & 0.04 \\
\hline Deceitfulness & $1.19(019)$ & $1.32(0.31)$ & 0.51 \\
\hline Depressiveness & $1.15(0.18)$ & $1.43(0.51)$ & 0.74 \\
\hline Distractibility & $1.48(0.33)$ & $1.88(0.65)$ & 0.78 \\
\hline Eccentricity & $1.42(0.60)$ & $1.47(0.57)$ & 0.09 \\
\hline Emotional Lability & $1.71(0.49)$ & $2.15(0.70)$ & 0.73 \\
\hline Grandiosity & $1.42(0.33)$ & $1.34(0.35)$ & 0.24 \\
\hline Hostility & $1.30(0.60)$ & $1.72(0.52)$ & 1.00 \\
\hline Impulsivity & $1.30(0.49)$ & $1.54(0.51)$ & 0.57 \\
\hline Intimacy Avoidance & $1.56(0.33)$ & $1.26(0.32)$ & 0.61 \\
\hline Irresponsibility & $1.23(0.29)$ & $1.33(0.37)$ & 0.33 \\
\hline Manipulativeness & $1.26(0.31)$ & $1.53(0.65)$ & 0.54 \\
\hline $\begin{array}{l}\text { Perceptual } \\
\text { dysregulation }\end{array}$ & $1.35(0.62)$ & $1.42(0.31)$ & 0.23 \\
\hline Perseveration & $1.37(0.32)$ & $1.64(0.43)$ & 0.71 \\
\hline $\begin{array}{l}\text { Restricted } \\
\text { Affectivity }\end{array}$ & $1.67(0.45)$ & $1.62(0.57)$ & 0.10 \\
\hline Rigid Perfectionism & $1.76(0.52)$ & $1.78(0.56)$ & 0.04 \\
\hline Risk Taking & $2.03(0.30)$ & $2.05(0.58)$ & 0.04 \\
\hline $\begin{array}{l}\text { Separation } \\
\text { Insecurity }\end{array}$ & $1.16(0.18)$ & $1.78(0.81)$ & 1.06 \\
\hline Submissiveness & $1.44(0.40)$ & $1.60(0.55)$ & 0.33 \\
\hline Suspiciousness & $1.62(0.29)$ & $2.02(0.46)$ & 1.04 \\
\hline $\begin{array}{l}\text { Unusual beliefs and } \\
\text { exp. }\end{array}$ & $1.82(0.67)$ & $1.41(0.52)$ & 0.68 \\
\hline Avoidance & $1.47(0.39)$ & $1.40(0.31)$ & 0.20 \\
\hline
\end{tabular}

Note. $d \geq .20$ in bold. 


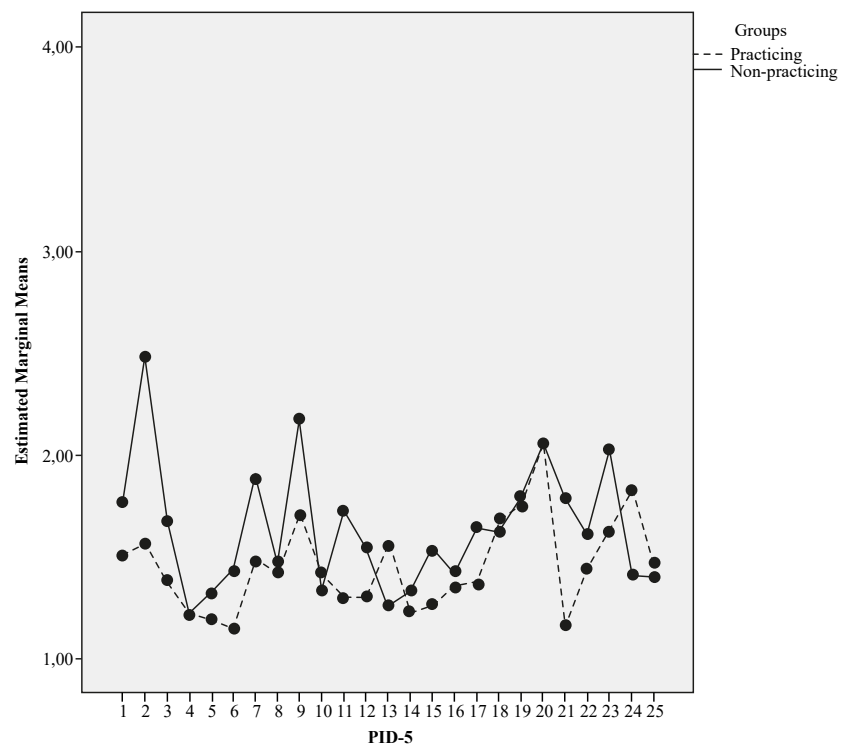

Figure 2. Profile of the groups in the PID-5 facets. 1.Anhedonia;2.Anxiety; 3.Attention Seeking; 4. Callousness; 5. Deceitfulness; 6. Depressivity; 7. Distractibility; 8. Eccentricity; 9. Emotional Lability; 10. Grandiosity; 11. Hostility; 12. Impulsivity; 13. Intimacy avoidance; 14. Irresponsibility; 15. Manipulativeness; 16. Perceptual dysregulation; 17. Perseveration; 18. Restricted affectivity; 19. Rigid perfectionism; 20. Risk taking; 21. Separation Insecurity; 22. Submissiveness; 23. Suspiciousness; 24. Unusual beliefs and experiences; 25. Avoidance.

In addition to the data presented, a logistic regression analysis was also performed to verify which dimensions best predict the participants' group, considering both IDCP and PID-5. According to the analysis, the facets Anxiousness, Rigid Perfectionism and Suspiciousness make up the best predictive set, with $\mathrm{r}_{\text {Cox }}^{2}=0.51$ and $\mathrm{r}^{2}{ }_{\text {Nagelkerke }}=0.69$. Data on the final set of predictor variables can be observed in Table 3 .

Table 3

Data of the predictor variables in the final model of logistic regression analysis

\begin{tabular}{lcccc}
\hline & B & E.P. & $d f$ & $p$ \\
\cline { 2 - 5 } Anxiety & 3.810 & 1.081 & 1 & .000 \\
Rigid perfectionism & -1.775 & .789 & 1 & .024 \\
Suspiciousness & 2.628 & 1.297 & 1 & .043 \\
Constant & -8.458 & 2.815 & 1 & .003 \\
\hline
\end{tabular}

It is verified that the Anxiousness facet was the one that contributed the most to the model and the facet Rigid Perfectionism was the one that least contributed (besides presenting a negative relation). It is also noteworthy that comparisons between means (ANOVA) were carried out in an exploratory way, with differences between practitioners according to the styles of meditation (concentration and mindfulness), number of times practicing meditation per week and number of times during the day. However, no significant differences were found in these comparisons.

\section{Discussion}

The data show a lower intensity of pathological personality traits in meditation practitioners compared to the group of non-practitioners in almost all dimensions and facets, both in IDCP and PID-5, partially confirming the h1 of this study, considering some facets of PID-5. The predominance of pathological or less healthy characteristics in non-practitioners found in other studies is corroborated in the present research (Campanella et al., 2014; Fossati et al., 2012; Leung \& Singhal, 2004; Menezes \& Dell'Aglio, 2009; van den Hurk et al., 2011). In fact, meditation practitioners are expected to exhibit less pathological personality profiles in relation to people who do not practice since this technique provides improvements in stress management, emotional benefits and social behavior, and also development of maturity, and other aspects, which are considered to be preventive of personality disorders (Campanella et al., 2014; Kabat-Zinn, 2003; Tang et al., 2007).

A detailed analysis of the data obtained, beyond the general intensity in the dimensions and facets of the instruments, allowed to investigate the confirmation of h2 of this study. In IDCP, non-practitioners scored higher in all dimensions, with Mood Instability, Dependence, and Impulsivity being the dimensions with the greatest discrepancy between the groups. Therefore, h2 is corroborated in the IDCP dimensions. This piece of data indicates that the individuals in this group tend to present mood swings and irritability characteristics, being able to present impulsive and extreme reactions, besides the inability to make decisions based on their own criteria, depending on others for this, and tendency to present impulsive attitudes without evaluating the consequences, creating conflicting situations. These data are supported by the results reported by Barnhofer, Duggan and Griffith (2011), Campanella et al. (2014), Menezes (2009) and Van den Hurk et al. (2011). In addition, it is worth mentioning that the dimension Mood Instability of the IDCP is related to more global aspects of psychopathology and the dimension Impulsivity seems to be composed of items with more pathological content (Carvalho \& Primi, 2015; Carvalho, Primi, et al., 2014); still on the Impulsivity score, data on the literature suggest lower scores in impulsivity measures by meditation practitioners (Burg, Wolf, \& Michalak, 2012; Zylowska et al., 2008). Significantly higher scores in these dimensions seem to indicate that the practice of meditation per se or the predisposition to this practice may function as a protective factor for the development of personality pathologies. Future studies should investigate whether the practice or predisposition is more related to lower scores on measures of pathological personality traits.

Despite the evident discrepancy between the groups of meditators and non-meditators in the IDCP, it should be 
noted that the largest and smallest means obtained by the two groups were in the same dimensions; that is, the differences between the groups tend to be more quantitative in terms of severity of pathological traits and less qualitative, since the profiles are similar in their format. Complementarily, in four dimensions of the IDCP (Eccentricity, Isolation, Attention Seeking and Conscientiousness) there were no significant differences between the means of the two groups, despite the higher score for non-practitioners. Regarding Eccentricity, no data were found in the literature that focused on this aspect of personality in practitioners.

Concerning the Isolation dimension, meditation practitioners are encouraged to cultivate and contemplate silence and seek to move away from social relationships at specific moments in everyday life to practice their meditative practices more deeply (Zylowska et al., 2008). Moreover, detachment is one of the central concepts of Eastern philosophies and one of the main concepts present in metacognition, through which meditation practitioners develop a greater distance and a phenomenological attitude of their relations with reality, including social and affective relations, which may have contributed to the scores of practitioners in this dimension in relation to non-practitioners (Menezes, 2009; Shapiro et al., 2006), justifying some increase in the items of this dimension for the group. These hypotheses should be investigated in future studies.

Regarding the non-expressive differences between the Attention Seeking and Conscientiousness dimensions (Carvalho, Sette, Capitão, \& Primi, 2014; Carvalho, Souza, \& Primi, 2014), it should be noted that, in previous studies, the need for revision of these dimensions was pointed out, mainly due to the tendency of the items to be less related to pathological functions, that is, the mean of the general population and that of pathological groups were not statistically different. The nondistinction between groups in which quantitative differences in severity of pathological traits are expected corroborates the results previously presented (Carvalho \& Primi, 2015).

In relation to the performance of the groups in the PID5 facets, more qualitative distinctions were found in the profiles of the groups by the PID-5 in comparison to the PID-5, and the practitioners presented higher scores in some dimensions. The facets in which the practitioners presented higher scores were Grandiosity, Avoidance of Intimacy, Unusual beliefs and experiences and Avoidance, which was not expected; however, it should be noted that the hypotheses currently raised for the Eccentricity and Isolation dimensions of the IDCP may be true for the PID-5 facets Avoidance of Intimacy, Avoidance, and unusual beliefs and experiences, since the first two are related to the tendency to not relate to others and isolate, and the latter to demonstrate atypical styles and thoughts (Krueger et al., 2011). Differently from what was evidenced with IDCP, h2 was not corroborated for the facets of PID-5.

Regarding the scores observed for Grandiosity, distinctly from the expressive differences $(d=0.65)$ and with a higher score for non-practitioners in the IDCP Grandiosity, in the PID5 only a small difference was observed, although expressive, with a higher mean for practitioners, going against what was hypothesized in this study (h1). It is worth noting that both sets of items refer to the tendency towards self-entitlement and depreciation of others, however, there are also items in the IDCP dimension that refer to persecution delusions and need for recognition (Carvalho \& Primi, 2015; Krueger et al., 2011). That is, although they focus on the same pathological functioning and have the same name, there are some differences in the composition of these two item arguments, so that the IDCP dimension presented data corroborating the h1 of this study, which did not occur with the facet of the PID-5.

Despite the discrepancy in what was observed for Grandiosity (IDCP and PID-5), similarities were found in the performance of practitioners and non-practitioners in the responses to the two tests used. Similar to the IDCP, there were high scores on the Anxiousness and Emotional Lability dimensions for the group of non-practitioners, with content related to Mood Instability (IDCP); Hostility with content related to Aggressiveness (IDCP); Separation Insecurity related to Dependency (IDCP); and Suspiciousness related to Distrust (IDCP).

Still on the PID- 5 scores, meditators presented the highest mean values in the facets unusual beliefs and experiences, Emotional Lability and Suspiciousness, which also occurred in other group, in addition to the facet Anxiousness. In this case, there is a more quantitative difference in the presence of atypical behaviors and thoughts, tendency to present mood swings and to suspect people, with difficulties in establishing bonds of trust, so that non-practitioners presented higher scores in these facets, besides also being more likely to worry about the future (anxiousness). Specifically regarding the tendency of practitioners to present less anxiousness in relation to non-practitioners, this was an expected fact that corroborates the literature (Menezes, 2009; Zylowska et al., 2008); the literature also supports the tendency of nonpractitioners to have greater difficulty in trusting others (van den Hurk et al., 2011).

As regards the lower scores in PID-5, in the facets Depressivity, Irresponsibility and Deceitfulness, according to Paul et al. (2012), meditation acts as protective and preventive of depressive states. The results of Menezes (2009) presented low levels of irresponsibility among practitioners; and the study by Campanella et al. (2014) supports the tendency of practitioners to be less likely to deceive people, since they tend to be more gregarious people with social concerns.

Afterwards, the regression analysis indicated as the best group of predictor variables the PID-5 facets Anxiousness, Rigid Perfectionism and Suspiciousness, in which nonpractitioners obtained the highest scores. The joint use of these three facets allows the professional to predict from $51 \%$ to $69 \%$ between groups of practitioners and non-practitioners. Future studies should seek to investigate the possibility of replicating these data and to deepen the knowledge of these pathological traits in the studied groups.

Finally, the other analyses did not find significant differences between the two different types of meditation, 
i.e., mindfulness and concentration. It should be pointed out that this is an initial study, which also attempted to investigate differences within meditators, however, with a substantial reduction in the sample, given the division of the group. Future studies should seek to deepen the search for possible differences between groups considering the type of meditation practiced, besides other variables such as meditation time. It should be noted that previous studies verified more pronounced differences in personality traits among meditators with more meditative practice time compared to less experienced or non-practicing individuals (Campanella et al., 2014; Menezes, 2009; van den Hurk et al., 2011).

The present study sought to contribute to the knowledge related to the impacts of meditation on personality traits. For this purpose, practitioners and non-practitioners were evaluated and their profiles compared in measures of assessment of pathological personality characteristics. H1 was partially corroborated, with the exception of some facets of PID-5. H2 was also partially corroborated, and the expected increases for IDCP were observed, but not for the PID-5 facets.

Some limitations should be considered related to the cross-sectional study design (therefore differences may reflect the search for meditation itself), and to the sample size (especially regarding logistic regression analysis), so that future studies should seek to replicate the findings of this research. Also concerning the sample, it should be considered that the practitioners and non-practitioners presented a statistical distinction in terms of age and psychiatric treatment, which may bring some bias to the observed data (e.g., younger group presenting more impulsivity), besides heterogeneity in length of practice (group of practitioners) and types of meditation. Regarding the instruments, it should be pointed out that only self-report measures were used, and it should also be considered that three total scores obtained internal consistency lower than .70 , but especially a fourth total score was lower than .60. Finally, it should also be considered the predisposition of non-meditators for the practice of meditation, since it is possible that the predisposition for this activity itself sets up changes in personality profiles.

\section{References}

Barnhofer, T., Duggan, S. D., \& Griffith, J. W. (2011). Dispositional mindfulness moderates the relation between neuroticism and depressive symptoms. Personality and Individual Differences, 51(8), 958-962. doi:10.1016/j. paid.2011.07.032

Burg, J. M., Wolf, O. T., \& Michalak, J. (2012). Mindfulness as self-regulated attention: Associations with heart rate variability. Swiss Journal of Psychology, 71(3), 135-139. doi:10.1024/1421-0185/a000080
Campanella, F., Crescentini, C., Urgesi, C., \& Fabbro, F. (2014). Mindfulness-oriented meditation improves self-related character scales in healthy individuals. Comprehensive Psychiatry,55(5), 1269-1278. doi:10.1016/j.comppsych.2014.03.009

Carvalho, L. F., \& Primi, R. (2015). Development and internal structure investigation of the Dimensional Clinical Personality Inventory. Psicologia: Reflexão e Crítica, 28(2), 322-330. doi:10.1590/1678-7153.201528212

Carvalho, L. F., \& Primi, R. (2016). Prototype matching of personality disorders with the Dimensional Clinical Personality Inventory. Psicologia: Teoria e Pesquisa, 32(2), e322214. doi:10.1590/0102-3772e322214

Carvalho, L. F., Primi, R., \& Stone, G. E. (2014). Psychometric properties of the Inventário Dimensional Clínico da Personalidade (IDCP) using the rating scale model. Avances en Psicología Latinoamericana, 32(3), 433-446. doi:10.12804/ap132.03.2014.09

Carvalho, L. F., Sette, C. P., Capitão, C. G., \& Primi, R. (2014). Propriedades psicométricas da versão revisada da dimensão necessidade de atenção do Inventário Dimensional Clínico da Personalidade [Psychometric properties of the revised attention seeking dimension of the Inventário Dimensional Clínico da Personalidade]. Temas em Psicologia, 22(1), 147-160. doi: 10.9788/TP2014.1-12

Carvalho, L. F., Souza, B. D. B., \& Primi, R. (2014). Psychometric properties of the revised conscientiousness dimension of Inventário Dimensional Clínico da Personalidade (IDCP). Trends in Psychiatry and Psychotherapy, 36(1), 23-31. doi:10.1590/2237-6089-2013-0024

Fossati, A., Porro, F. V., Maffei, C., \& Borroni, S. (2012). Are the DSM-IV personality disorders related to mindfulness? An Italian study on clinical participants. Journal of Clinical Psychological, 68(6), 672-683. doi: $10.1002 /$ jclp. 21848

Giluk, T. L. (2009). Mindfulness, Big-Five and affect: A meta-analysis. Personality and Individual Differences, 47(8), 805-811. doi:10.1016/j.paid.2009.06.026

Kabat-Zinn, J. (2003). Mindfulness-based interventions in context: Past, present, and future. Clinical Psychology: Science and Practice, 10(2), 144-156. doi:10.1093/clipsy.bpg016

Khoury, B., Lecomte, T., Fortin, G., Masse, M., Therien, P., Bouchard, V., ... Hofmann, S. G. (2013). Mindfulness-based therapy: A comprehensive metaanalysis. Clinical Psychology Review, 33(6), 763-771. doi:10.1016/j.cpr.2013.05.005 
Krueger, R. F., Derringer, J., Markon, K. E., Watson, D., \&Skodol, A. E. (2011). Initial construction of a maladaptive personality trait model and inventory for DSM-5. Psychological Medicine, 42(9), 1879-1890. doi:10.1017/S0033291711002674

Leung, Y., \& Singhal, A. (2004). An examination of the relationship between QiQong meditation and personality. Social Behavior and Personality, 32(4), 313-320. doi:10.2224/sbp.2004.32.4.313

Menezes, C. B. (2009). Por que meditar? A relação entre o tempo de prática da meditação, o bem-estar psicológico e os traços de personalidade [Why meditate? The relationship between the time of meditation practice, the psychological well-being and personality traits] (Master's thesis). Retrieved from http://www.lume.ufrgs.br/bitstream/ handle/10183/15910/000690151.pdf?sequence=1

Menezes, C. B., \& Dell'Aglio, D. D. (2009). Os efeitos da meditação à luz da investigação científica em Psicologia: Revisão de literatura [The effects of meditation in the light of scientific research in Psychology: Literature review]. Psicologia: Ciência e Profissão, 29(2), 276-289. doi: 10.1590/S1414-98932009000200006

Millon, T. (2011). Disorders of personality: Introducing a DSM/ICD spectrum from normal toabnormal (3rd ed.). Mahwah, NJ:John Wiley \& Sons.

Millon, T., Grossman, S., Millon, C. M., Meagher, S. E., \& Ramnath, R. (2004). Personality disorders in modern life (2nd ed.). Mahwah, NJ:John Wiley \& Sons.

Noguchi, M. S. (2015). Meditação, saúde coletiva e fonoaudiologia: Um diálogo em construção. Distúrbios da Comunicação, 27(3), 642-653. Retrieved from https:// revistas.pucsp.br/index.php/dic/article/view/22186/17737

Paul, N. A., Stanton, S. J., Greeson, J. M., Smoski, M. J., \& Wang, L. (2012). Psychological and neural mechanisms of trait mindfulness in reducing depression vulnerability. Social Cognitive and Affective Neuroscience, 8(1), 56-64. doi:10.1093/scan/nss070

Primi, R., Carvalho, L. F., Bandeira, D. R., Yazigi, L, Oliveira, S. E. S., \& Rossi, A. A. (2013). Versão brasileira do PID-5. (Manuscript not published).

Schroeder, M. L., Wormworth, J. A., \& Livesley, W. J. (1992). Dimensions of personality disorder and their relationships to the Big Five dimensions of personality. Psychological Assessment, 4(1), 47-53. doi:10.1037/1040-3590.4.1.47

Shapiro, S. L., Carlson, L. E., Astin, J. A., \& Freedman, B. (2006). Mechanisms of mindfulness. Journal of Clinical Psychology, 62(3), 373-386. doi:10.1002/jclp.20237
Tang, Y. Y., Ma, Y., Wang, J., Fan, Y., Feng, S., Lu, Q., ... Posner, M. I. (2007). Short-term meditation training improves attention and self-regulation. Proceedings of the National Academy of Sciences of the United States of America, 104(43),17152-17156. doi:10.1073/pnas.0707678104

van den Hurk, P. A. M., Wingens, T., Giommi, F., Barendregt, H. P., Speckens, A. E. M., \& van Schie, H. T. (2011). On the relationship between the practice of mindfulness meditation and personality: An exploratory analysis of the mediating role of mindfulness skills. Mindfulness, 2(3), 194-200. doi: 10.1007/s12671-011-0060-7

Zylowska, L., Ackerman, D. L., Yang, M. H., Futrell, J. L., Horton, N. L., Hale, T. S., ... Smalley, S. L. (2008). Mindfulness meditation training in adults and adolescents with ADHD: A feasibility study. Journal of Attention Disorders, 11(6), 737-746. doi: $10.1177 / 1087054707308502$

Lucas de Francisco Carvalho is a Professor of the Programa de Pós-Graduação Stricto Sensu em Psicologia of the Universidade São Francisco.

Wellington Arruda is a psychologist-graduated from the Universidade São Francisco.

Received: Aug. 19, 2015

1st Revision: Dec. 22, 2015

Approved: Nov. 11, 2016

How to cite this article:

Carvalho, L. F., \& Arruda, W. (2018). Pathological personality traits assessment in meditation practitioners and nonpractitioners. Paidéia (Ribeirão Preto), 28, e2804. doi: http://dx.doi.org/10.1590/1982-4327e2804. 